\title{
Effect of temperature stress on the early vegetative development of Brassica oleracea L.
}

\author{
Víctor M. Rodríguez ${ }^{1}$, Pilar Soengas ${ }^{1}$, Virginia Alonso-Villaverde ${ }^{2}$, Tamara Sotelo ${ }^{1}$, María E. Cartea ${ }^{1}$ \\ and Pablo Velasco ${ }^{1 *}$
}

\begin{abstract}
Background: Due to its biennual life cycle Brassica oleracea is especially exposed to seasonal changes in temperature that could limit its growth and fitness. Thermal stress could limit plant growth, leaf development and photosynthesis. We evaluated the performance of two local populations of $B$. oleracea: one population of cabbage (B. oleracea capitata group) and one population of kale (B. oleracea acephala group) under limiting low and high temperatures.
\end{abstract}

Results: There were differences between crops and how they responded to high and low temperature stress. Low temperatures especially affect photosynthesis and fresh weight. Stomatal conductance and the leaf water content were dramatically reduced and plants produce smaller and thicker leaves. Under high temperatures there was a reduction of the weight that could be associated to a general impairment of the photosynthetic activity.

Conclusions: Although high temperatures significantly reduced the dry weight of seedlings, in general terms, low temperature had a higher impact in B. oleracea physiology than high temperature. Interestingly, our results suggest that the capitata population is less sensitive to changes in air temperature than the acephala population.

Keywords: Brassica, Physiology, Photosynthesis, Thermal stress

\section{Background}

Due to their sessile lifestyle plants are especially exposed to environmental changes that modulate their growth and development. Optimal plant growth takes place within more or less strict environmental conditions. Outside this optimal range, plants suffer stresses which limit their growth and productivity. In agriculture some of these abiotic stresses can be minimized by using irrigation and fertilization. Other stresses, however, are difficult to overcome and fluctuations in air temperature are a clear example. Variations in temperature are one of the principal factors that drive plant phenology. Stratification and vernalization are well known physiological processes that are triggered by transient exposure to low temperatures $[1,2]$. Seasonal changes in temperature also promote many developmental processes (i.e. flowering, germination or grain filling) $[3,4]$. However, above or below certain

\footnotetext{
* Correspondence: pvelasco@mbg.csic.es

'Group of Genetics, Breeding and Biochemistry of Brassicas. Misión Biológica de Galicia (MBG-CSIC), Apartado 28, 36080 Pontevedra, Spain

Full list of author information is available at the end of the article
}

thresholds, temperatures limit geographical distribution and productivity of many important crops.

Contrary to metazoans, plants do not have specialized cell types that allow perception of temperature fluctuations. The mechanisms through which plants perceive temperature has been proposed to be similar for both, high and low temperatures, although the intracellular signaling and physiological response differ between both stimuli [5]. The first structure that responds to temperature fluctuations is the plasma membrane. Both, high and low temperatures, cause changes in the fluidity of this structure which activates an intracellular signal cascade [6]. Associated with the plasma membrane, the cytoskeleton is another sensor of temperature fluctuations. Exposure of plants to growthlimiting temperatures induces the depolymerization of microtubules and microfilaments $[7,8]$. These two structures are intimately involved in cell morphogenesis [9] and its rearrangement may explain variations of the leaf shape in plants growth under extreme temperatures [10].

Probably, the cellular component most sensitive to temperature fluctuations is the photosynthetic apparatus. The primary targets of thermal stress on the photosynthetic 
apparatus in plants are the photosystem II (PSII) and the carbon fixation by Rubisco [11]. An early effect of temperature in the photosynthetic apparatus is the inhibition of the activity of the PSII. This phenomenon has been broadly studied in the last decade to the extent that the chlorophyll fluorescence analysis is nowadays an experimental approach routinely used in physiological studies [12, 13]. When illuminated, the antennae within the photosynthetic membrane absorb energy that is transferred to the reaction center. The fraction of energy that could not be trapped by the reaction center is then dissipated as heat or fluorescence. The amount of emitted fluorescence could be easily measured through fluorescence spectroscopy. Upon illumination the fluorescence emission is not constant but exhibits a fast rise followed by a decline to reach a steady level [14]. When fluorescence values recorded during the fast rise are plotted against time on a logarithmic scale (OJIP curve), different phases became visible [15]. Based on the appearance of these phases Strasser et al. [16] have developed a concept that tries to describe and explain changes in the rise kinetics and amplitudes of these phases in response to stress conditions. Based on this concept, equations to calculate a set of parameters were derived (the so-called JIP-test).

Crops with a biennial life-cycle are exposed to seasonal temperature variations ranging from below zero to more than $40^{\circ} \mathrm{C}$. Among biennial plants, Brassica oleracea L. stands out as one of the most important species in the world from an economical point of view. Human selection has led to the development of a range of cultivars within this species in which different organs are used for human or livestock consumption [17]. Originally domesticated in Atlantic coastal regions of Europe, cultivars of this species are nowadays cultivated worldwide and grown under a wide range of climate conditions. This wide diversity may be reflected in different mechanisms to respond to thermal stress among the different cultivars of this species. Recently, we have performed a study to elucidate the impact of high temperatures on a broad set of local populations of B. oleracea during early development [18]. The variability observed in this analysis prompted us to perform a more detailed analysis of the effect of thermal stress on the early development of B. oleracea. Therefore, the goal of the present investigation was to analyze the physiological response of two cultivars of $B$. oleracea grown under extreme temperatures mainly focused on the effect of stressful temperatures on the performance of the photosynthetic apparatus and leaf growth.

\section{Results and discussion}

We studied the effect of stressful temperatures on the early development of $B$. oleracea. Based on a previous evaluation, we selected two populations of $B$. oleracea (one cabbage and one kale population) that showed a good early development under heat conditions [18]. These two cultivars were also selected because they have a common origin (Northwestern Spain) and show similar seasonality. Preliminary evaluations allow us to stablish the limiting temperatures to carry out further evaluations (constant $12{ }^{\circ} \mathrm{C}$ for chilling experiments and constant $32{ }^{\circ} \mathrm{C}$ for heat experiments). Below $12{ }^{\circ} \mathrm{C}$ seedlings were unable to germinate and above $32{ }^{\circ} \mathrm{C}$ leaf expansion was dramatically compromised.

As expected, thermal stress produces a significant reduction of the fresh weight of the aerial part of both varieties (Fig. 1a). This reduction was especially marked when plants were grown under chilling conditions, since under such conditions fresh weight was reduced by $50 \%$ compared to values observed under control temperature $\left(20^{\circ} \mathrm{C}\right)$ (Fig. 1a). Curiously, plants grown under chilling conditions did not show a reduction of the dry weight compared to data obtained under control conditions (Fig. 1b), although they showed a significantly higher percentage of dry matter than plants grown under control or high temperature conditions (Fig. 1c), indicating a significant reduction of the leaf water content. Previous studies have reported that plants exposed to cold perform in a similar way as plants exposed to drought, concerning water content [19]. Our experiments were performed with excess of irrigation to remove the effect of drought from the physiological response, which could explain why there is not reduction of the water content in plants exposed to high temperature conditions. Similar results were previously reported in Nicotiana tabacum [20]. Although, the mechanism by which cold temperatures influence the hydric status of the plant is unclear, our results suggest that, at least under our experimental conditions, these are independent of those observed under high temperatures and also independent of the water available.

The leaf water content is the result of the equilibrium between water absorption and evapotranspiration. Water absorption through the roots is promoted by increasing temperatures as well as the movement of water within the plant that has been attributed to changes in membrane fluidity and permeability, changes in water viscosity or a combination of both [21-23]. Likewise, the hydraulic conductance of the plant changes linearly with temperature and stomata can directly respond to variations in this parameter by increasing transpiration [22, 24]. For this reason we measured different parameters related to stomata anatomy and functionality. In our experiment, the number of stomata per $\mathrm{mm}^{2}$ was not significantly affected by the temperature in the acephala group, whereas in the capitata group an increase was observed in both stress conditions (Fig. 2a). The size of these stomata was affected by temperature in both groups. Smaller stomata were observed under chilling conditions compared to the size observed under control conditions 


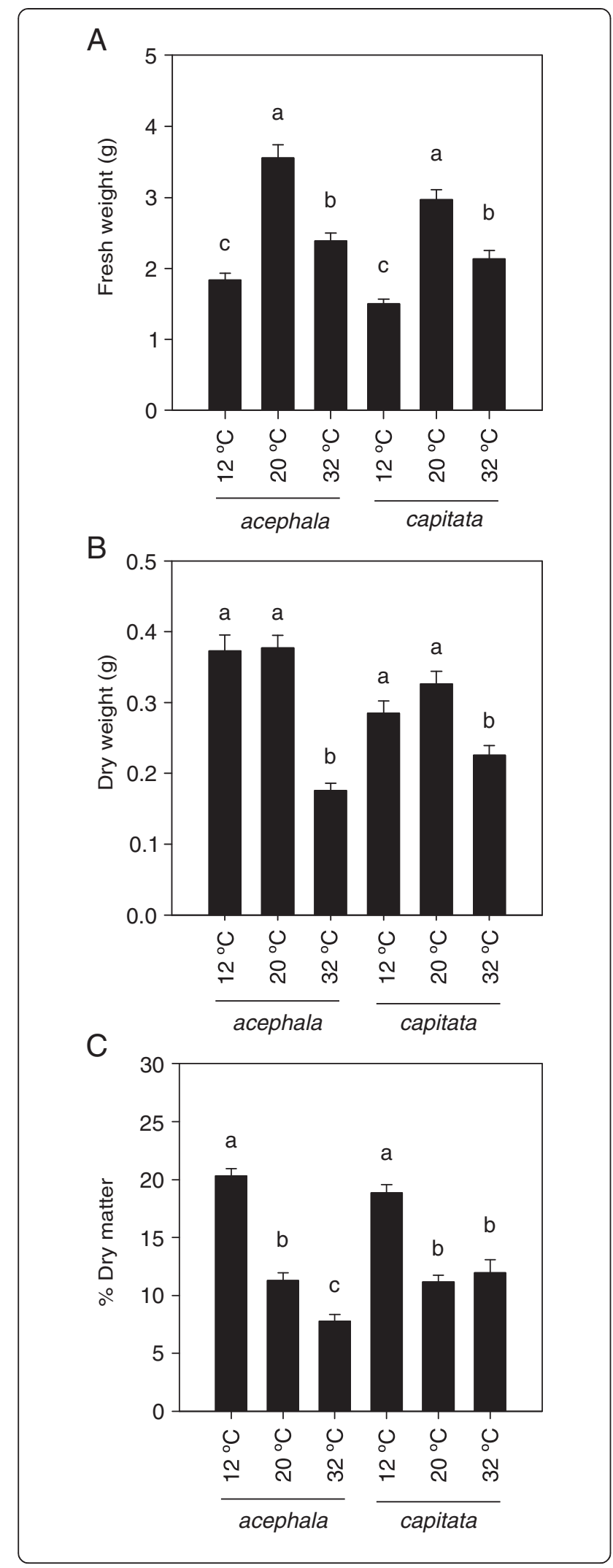

Fig. 1 Effect of thermal stress on biomass production of two cultivars of Brassica oleracea exposed to chilling $\left(12^{\circ} \mathrm{C}\right)$ and high $\left(32^{\circ} \mathrm{C}\right.$ ) temperatures. a. Fresh weight ( $\mathrm{g}$ ) of the aerial part of seedlings grown under cold and heat conditions. $\mathbf{b}$. Dry weight (g) of the aerial part recorded after drying in a oven at $80^{\circ} \mathrm{C}$ until constant weight. c. Percentage of dry weight. In all pannels bars denote the mean of 20 measurements \pm SE. Mean values within each cultivar with different letters are signifficantly different $(P<0.05)$

(Fig. 2b). In the case of the capitata group there was also a reduction of the size of the stomata under heat conditions compared to the size observed under control conditions. However, the stomatal-related trait most affected by temperature was the stomatal conductance. For both groups the lowest conductance was recorded under chilling conditions (Fig. 2c). Interestingly, under heat conditions, the stomatal conductance of the acephala group significantly increases compared to control conditions whereas the percentage of dry matter decreases when temperature increases (Fig. 1b, Fig. 2c), in concordance with previous theories exposed by $[22,23]$. However, in the case of the capitata group there are no differences between percentage of dry matter and stomatal conductance between 20 and $32{ }^{\circ} \mathrm{C}$, suggesting that plants from the capitata group are more tolerant to high temperatures.

Low temperatures also modulate leaf growth. Plants grown under chilling conditions developed smaller leaves than those grown under control or heat conditions (Fig. 3a and b). Growth under low temperatures often results in significant alterations in leaf morphology. The most noticeable effect is a reduction in specific leaf area (the ratio of leaf area to leaf dry mass) [25]. It is also remarkable that under cold conditions the leaves become thicker than those observed under control or high temperature (Fig. 3c). It has been previously reported that plants grown under chilling conditions show reduced leaf expansion and increased mesophyll thickness [26, 27].

Since temperature affects leaf size, we wondered whether it could affect also the leaf shape. Juvenile leaves of $B$. oleracea have an oval shape. Although the leaves of both varieties follow this general rule, under control conditions the acephala group developed leaves slightly longer than its width, whereas the opposite behavior was observed in the leaves of the capitata group (see Additional file 1: Figure S1). There was no effect of temperature in the leaf shape of the capitata group, whereas the leaves of the acephala group developed under thermal stress become longer than its width (see Additional file 1: Figure S1).

At the autotrophic stage plant growth strongly depends on the capacity of the photosynthetic apparatus to fix carbon. Photosynthesis is one of the most affected cellular reactions by environmental changes; concretely the PSII activity is especially sensitive to thermal stress [5]. An 


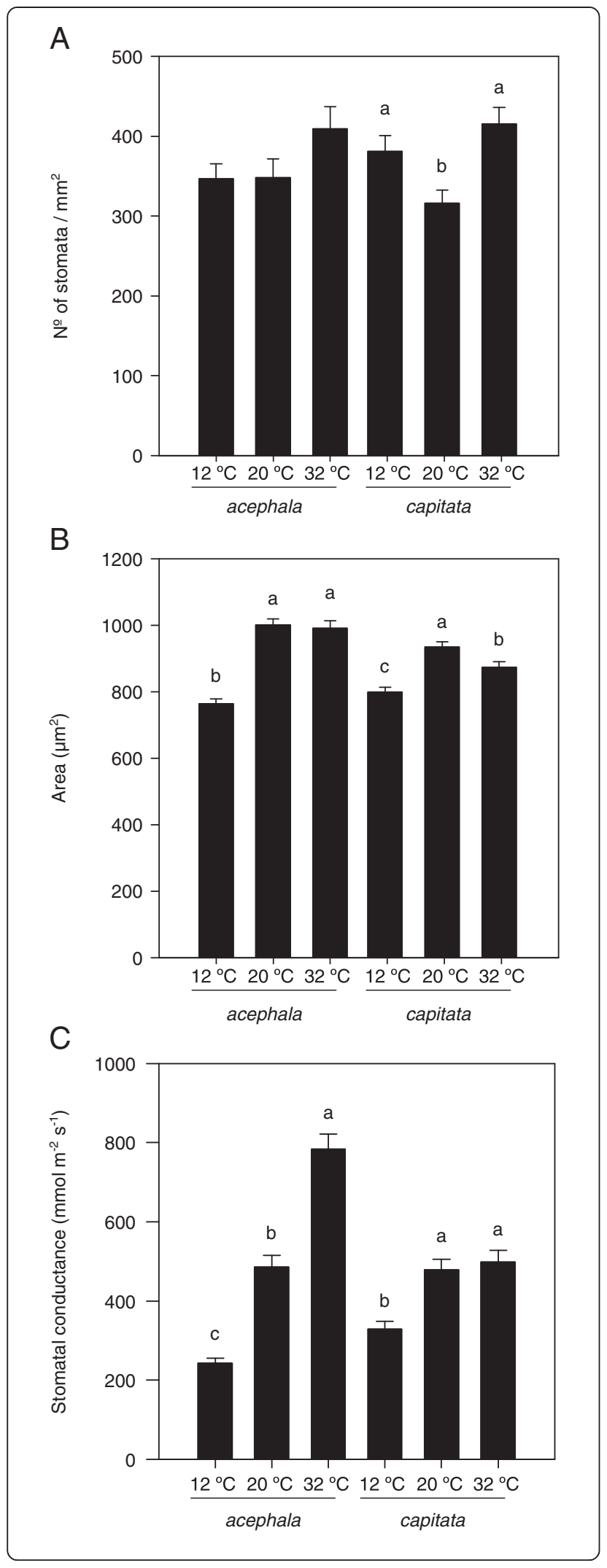

Fig. 2 Incidence of temperature on anatomical and functional characteristics of stomata in two cultivars of Brassica oleracea exposed to chilling $\left(12^{\circ} \mathrm{C}\right)$ and high $\left(32^{\circ} \mathrm{C}\right)$ temperatures. a. Number of stomata per $\mathrm{mm}^{2}$. b. Area of stomata $(\mu \mathrm{m})$. c. Stomatal conductance measured with a leaf porometer. In all panels bars denote the mean of at least 20 measurements \pm SE. Mean values within each cultivar with different letters are signifficantly different $(P<0.05)$

indirect approximation to the activity of the PSII could be easily measured by using a portable fluorimeter. To determine which of the different stages of the electronic transport could be affected by thermal stress we plotted the fluorescence kinetics in a logarithmic time scale to obtain the so-called OJIP transient curve. The different steps that arise have been associated to different redox states of the components of the electron transport chain [28]. In our experiment, the fluorescence pattern during the first second after transient illumination was similar between the acephala and capitata groups grown under control conditions (Fig. 4a).

According to experimental data the OJIP transient curve could be divided in two mechanistic phases, the "photochemical phase" (O-J rise) and the "thermal phase" (J-I-P rise) [29]. Thermal stress induces a significant increase of fluorescence at the $\mathrm{O}$ step in the $B$. oleracea seedlings which is more prominent under heat than under chilling conditions (see Additional file 2: Figure S2). Under optimal conditions the $\mathrm{O}$ step represents the minimal fluorescence intensity $\left(\mathrm{F}_{0}\right)$ [30]. The $\mathrm{F}_{0}$ represents the fluorescence emission when all the primary quinone-type acceptors $\left(\mathrm{Q}_{\mathrm{A}}\right)$ of the reaction center are in the oxidized state. We observed a significant increase of the $F_{0}$, especially when seedlings were grown under high temperatures. Such an increase has been observed previously in other crops [31, 32], and it has been associated to a dissociation of part of the outer antenna from the rest of the PSII [33] or to a shift in the equilibrium between the electron acceptors $\mathrm{Q}_{\mathrm{A}}$ and $\mathrm{Q}_{\mathrm{B}}$ which enhance back electron transfer from $\mathrm{Q}_{B}$ to $\mathrm{Q}_{\mathrm{A}}[31,34]$. In this later scenario, $\mathrm{Q}_{\mathrm{A}}$ will remain partially reduced in darkness and the O-step no longer represents the $\mathrm{F}_{0}$.

Nevertheless, the fluorescence kinetics during the "photochemical phase" was similar to that observed under control conditions, indicating that the rate of $\mathrm{Q}_{\mathrm{A}}$ reduction during early photochemistry was not significantly affected by temperature [35]. This result was confirmed by quantifying the velocity of fluorescence rising during the first milliseconds following a dark to light transition which could be determined by the initial slope of fluorescence $\left(\mathrm{M}_{0}\right)$. This parameter was not significantly affected by temperature except for the acephala group under chilling conditions that showed an increase of the initial fluorescence (Fig. 4b). 


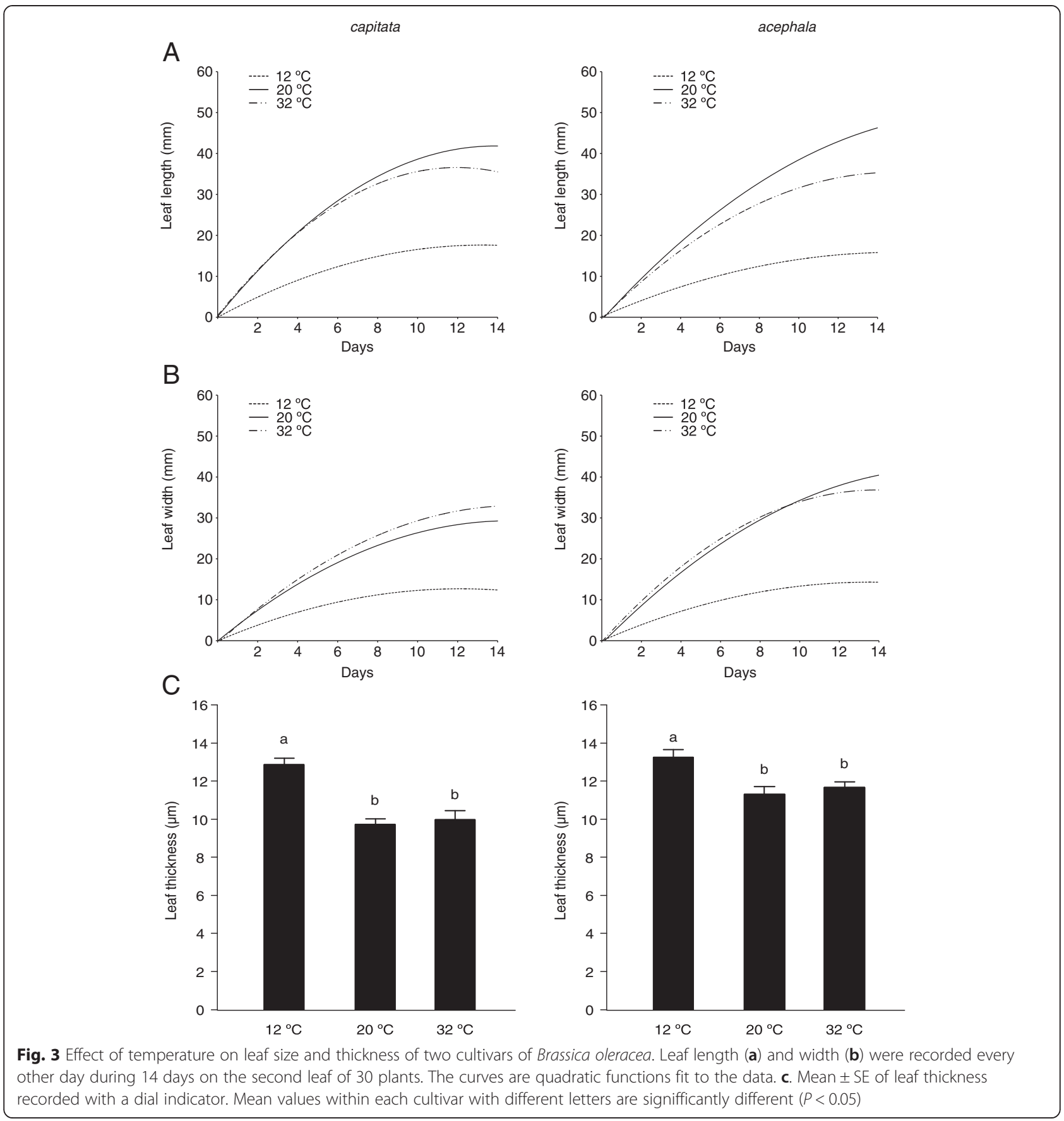

Several authors reported a new transient step (named K-step) in data obtained from plants cultivated under stress when the OJIP curve is represented as the kinetics of relative variable fluorescence $(\mathrm{Vt})$ in a logarithmic time scale, especially under heat stress [33, 36-38]. This step has been associated with damage to the donor side of PSII by thermal stress [35]. We did not observe an obvious K-step under our experimental conditions (data not shown).

The pattern of fluorescence transient varied among temperatures and cultivars in the "thermal phase" (Fig. 4a). A tendency to increase fluorescence values under high temperature was observed for both genotypes; whereas the opposite was observed under cold temperatures (see Additional file 2: Figure S2). The magnitude of such variation differed between cultivars, being the variation recorded on the capitata group less pronounced than that recorded on the acephala group. Beyond the differences in amplitude there were also differences in the rise kinetics that can be related to stoichiometric differences in the composition of the photosynthetic electron transport chain [39]. 

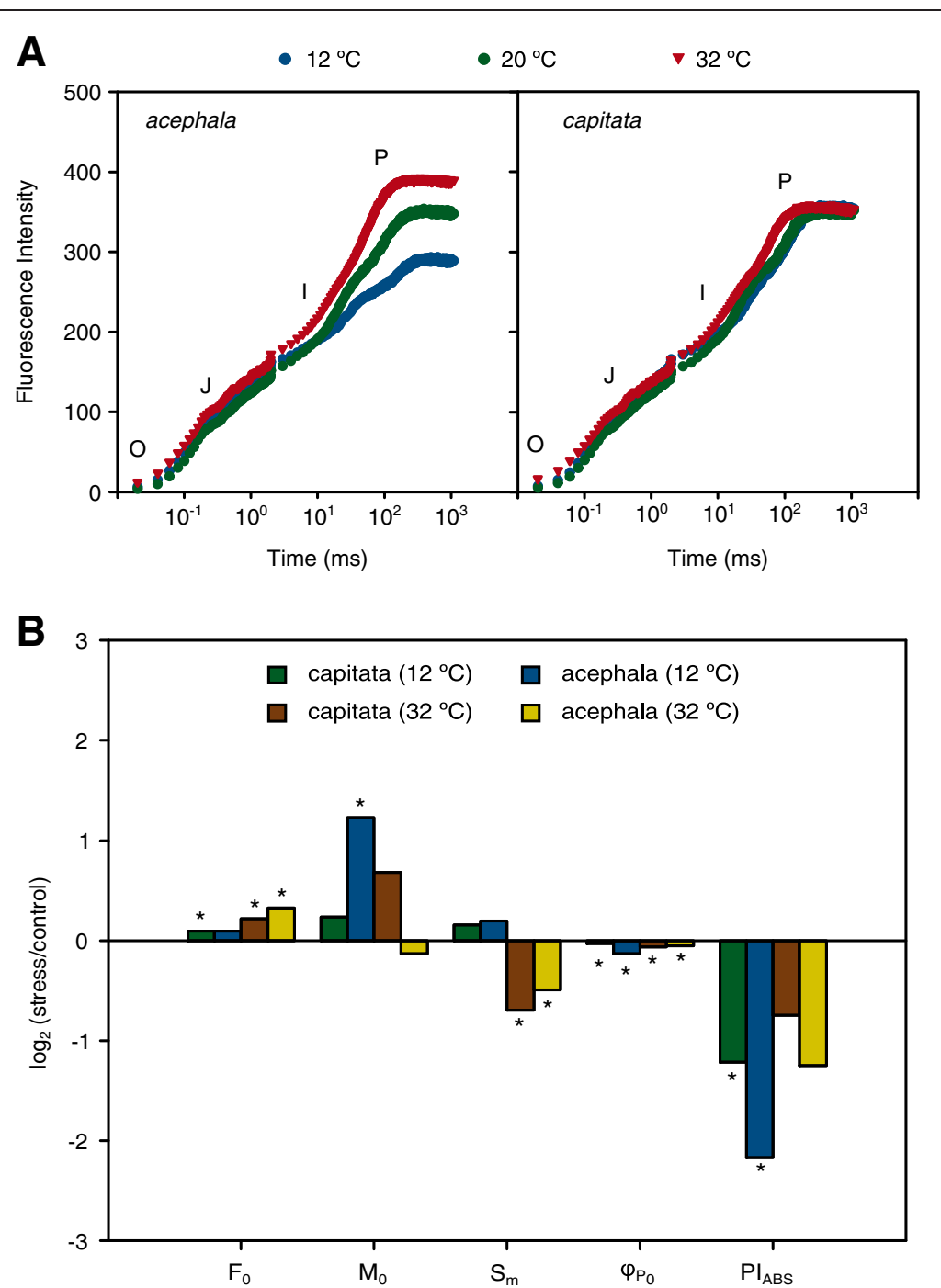

Fig. 4 Effect of temperature on the fluorescence transient and JIP test parameters of two cultivars of Brassica oleracea expossed to chilling $\left(12{ }^{\circ} \mathrm{C}\right)$ and high $\left(32^{\circ} \mathrm{C}\right)$ temperatures. a. Chlorophyll a fluorescence transient curve expressed on a logaritmic time scale. b. Different parameters ( $F_{0}$, minimal fluorescence; $M_{0}$, initial slope of the fluorescence transient; $S_{m}$, area above the OJIP transient; $\varphi_{p o}$, maximum quantum yield of primary photochemistry; PI, performance index of fast fluorescence transient in two cultivars of Brassica oleracea. Data from the control were used to normalized the different parameters. Log2-transformed normalized values are represented on ordinate. ${ }^{*} P<0.05$ (treatment vs. control)

Contrary to the "photochemical phase" there is a controversy in the literature about the molecular mechanisms behind the fluorescence kinetics at the "thermal phase" (for review see [29]). Duysens and Sweers [40] postulated in 1963 that the fluorescence changes reflect primarily changes in the redox state of $\mathrm{Q}_{\mathrm{A}}$, in a way that the maximum fluorescence is reach when the pool of $\mathrm{Q}_{\mathrm{A}}$ is completely reduced [29]. However, in the last decades, alternative models have been proposed that implies the involvement of second processes influencing the fluorescence rise [41]. Strasser et al. [42] carried out a simulation with three possible scenarios, considering a pure $\mathrm{Q}_{\mathrm{A}}$ model or the influence of an alternative quencher and they concluded that all these models fitted satisfactorily with the results. Since the JIP-test is based in a pure $\mathrm{Q}_{\mathrm{A}}$ model we interpreted our results based on this model, keeping in mind that alternative explanations may be considered.

An important parameter that influences the fluorescence kinetics is the multiple turn-over of $\mathrm{Q}_{\mathrm{A}}$ that is correlated to the area above the OJIP curve $\left(S_{m}\right)$ [16]. In our experiment, this area was not affected by chilling temperatures but significantly decreased when both varieties were exposed to high temperatures, indicating that fewer electron acceptors are available in the electron transport chain. However, due to the fact that both genotypes perform similarly, the $\mathrm{Q}_{\mathrm{A}}$ turn-over does not explain 
the differences observed in the fluorescence kinetics during the "thermal phase".

The overall performance of the activity of the PSII was estimated using the maximum quantum yield of primary photochemistry $\left(\phi_{\mathrm{PO}}\right)$ which is equivalent to the $\mathrm{Fv} / \mathrm{Fm}$ parameter [30]. Under chilling and heat conditions, this parameter was significantly reduced compared to values observed under control conditions, indicating that the PSII undergoes physiological changes due to thermal stress (Fig. 4b).

The photosynthetic energy flux may be divided in four different steps. These steps represent the photon flux absorbed by the antenna pigments and creating excited chlorophyll (ABS), the excitation energy that is channeled as trapping flux (TR), the excitation energy that creates an electron transport that leads to $\mathrm{CO}_{2}$ fixation (ET) and the energy that is dissipated as heat or fluorescence (DI) and are normalized by reaction center (RC). The performance of both varieties in these four steps was significantly different (Fig. 5). Chilling temperatures have a major impact increasing the energy absorbed (ABS/RC) and trapped $(\mathrm{TR} / \mathrm{RC})$ in the acephala group, whereas the electron transport flux (ET/RC) decreased. A concomitant increase in the dissipation flux (DI/RC) was observed, indicating that the efficiency of the photosynthesis was reduced. However, high temperatures have little impact in these fluxes in this group and just a slightly increase of the dissipated flux was observed.
The opposite behavior was observed in the capitata group. The performance of this group under chilling conditions was similar to that observed for the acephala group at heat conditions. However, under heat conditions acephala group showed an increase of the four steps studied, indicating that most energy is transmitted through the photosynthetic apparatus.

\section{Conclusions}

Our results suggest that the capitata population is less sensitive to changes in air temperature than the acephala group; low temperature has a high impact in B. oleracea physiology, especially on photosynthesis and fresh weight, although there was not effect on dry weight. Under high temperatures there was a reduction of the fresh weight that could be associated to a general impairment of the photosynthetic activity.

\section{Methods}

\section{Plant material and growth conditions}

One population of cabbage (B. oleracea capitata group) and one population of kale (B. oleracea acephala group) were obtained from the Brassica seed bank of the Mision Biológica de Galicia (CSIC-Spain). Seeds were planted in multi-pot trays filled with sterilized peat (Gramoflor GmbH \& Co. KG, Vechta, Germany) with one seed per cavity. Seedlings were grown under fluorescent light $\left(228 \mu \mathrm{mol} \mathrm{m} \mathrm{m}^{-2} \mathrm{~s}^{-1}\right)$ in a $14 \mathrm{~h}$ light $/ 10 \mathrm{~h}$ dark light regime

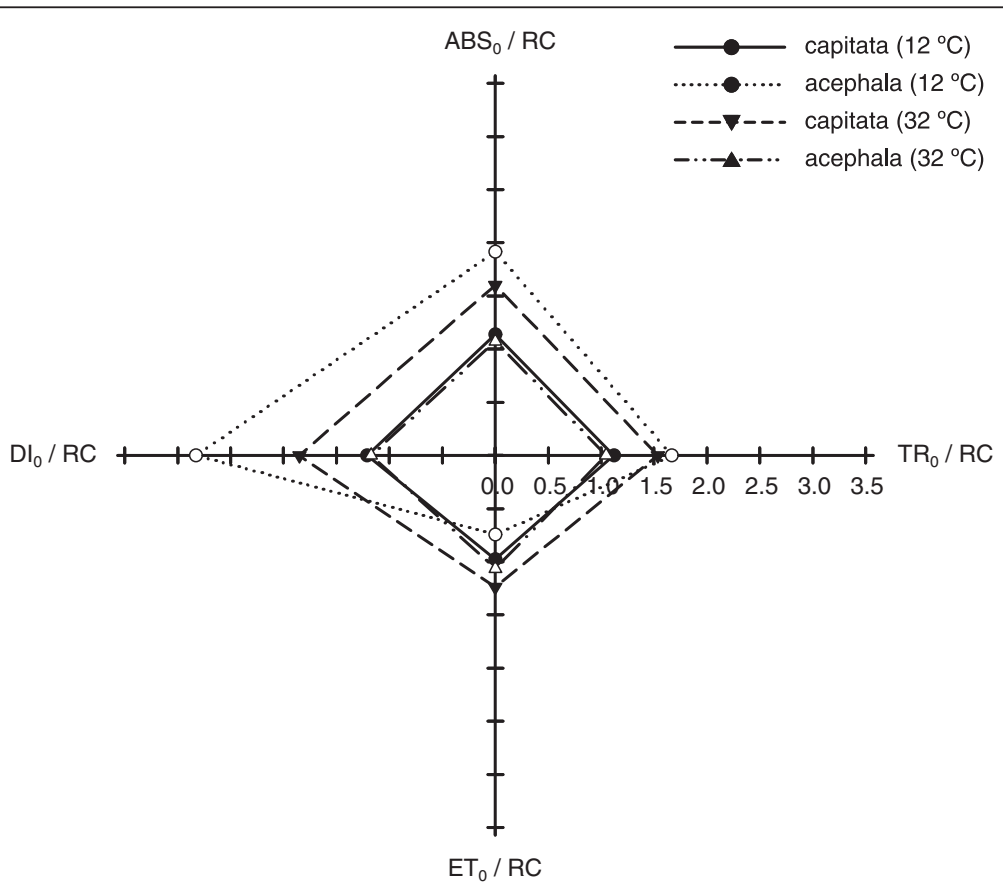

Fig. 5 Spider plot representation of specific fluxes per reaction center in two cultivars of Brassica oleracea expossed to control $\left(20^{\circ} \mathrm{C}\right)$, chilling $\left(12^{\circ} \mathrm{C}\right)$ and high $\left(32^{\circ} \mathrm{C}\right)$ temperatures. Energy fluxes are expressed based on the theoretical number of reaction centers (RC). Absorption per RC (ABS/RC); electron transport (ET/RC); trapping ( $\left(R_{0} / R C\right)$; dissipation ( $\left.D I_{0} / R C\right)$ 
and watered as needed. A constant day/night temperature regime was set up at $20 \pm 1{ }^{\circ} \mathrm{C}$ for control conditions. The thresholds of high and low temperatures were established experimentally. Heat experiment was performed at $32 \pm 1{ }^{\circ} \mathrm{C}$, since above this temperature seedling growth was dramatically reduced and leaf expansion compromised. Chilling experiment was established at $12 \pm 1{ }^{\circ} \mathrm{C}$, since lower temperatures reduced dramatically seed germination and seedling survival.

\section{Morphometric analysis}

Leaf growth rate was determined by measuring the maximal length (maximal length from the apical to the basal part of the leaf) and width (measured at the leaf mid-point) of the second leaf of 30 plants every other day until the 14th day after the first data was recorded. Measurements were recorded using a digital caliper (Metrica, Barcelona, Spain). Leaf thickness was measured in 20 plants at the end of the experiment with an AMES 212.1 dial indicator (B.C. AMES CO., Waltham, MA, USA).

\section{Physiological parameters}

Chlorophyll $a$ fluorescence was recorded in the second leaf of 20 plants from each population at the V4 developmental stage. Fluorescence was measured with a portable fluorometer (OS-30p Chlorophyll Fluorometer, OptiScience, Inc., Hudson, NH USA) and recorded up to $1 \mathrm{~s}$ with a data acquisition rate of 100 readings $\mathrm{ms}^{-1}$ for the first $2 \mathrm{~ms}$ and 1 reading $\mathrm{ms}^{-1}$ thereafter. Fluorescence transient was induced by red light of $3000 \mu \mathrm{mol} \mathrm{m}{ }^{-2} \mathrm{~s}^{-1}$ provided by an array of 3 light-emitting diodes (peak at $660 \mathrm{~nm}$ ) using plants dark adapted for 1 hour. Fluorescence data were analyzed according to the JIP test (see Additional file 3: Table S1) [16, 43].

Stomatal conductance was recorded using a SC-1 leaf porometer (Decagon Devices Inc., Pullman, WA, USA) in the second leaf of 20 plants per population and temperature at V4 developmental stage.

\section{Stomatal measurement}

Leaf printing was carried out following Chen et al. [44] with a few modifications. Briefly, a leaf print (approx. size $1 \times 1 \mathrm{~cm}$ ) was obtained from the base of the second leaf from 15 plants in a V4 developmental stage per population and temperature with transparent nail polish from the abaxial leaf lamina close to the principal nerve. Observations were made on a Nikon Eclipse E200 light microscope and the number of stomata per visual field $\left(0.196 \mathrm{~mm}^{2}\right)$ was recorded for each sample. Images were captured using a Nikon DS-F11 camera under bright field and the width and length of 15 stomata per plant of each population and temperature were measured using the ImageJ Software [45].

\section{Statistical analysis}

Analyses of variance were performed for each population using the procedure GLM of SAS [46] using temperatures as the classification variables. Temperature was considered as fixed. Comparisons of means were made by using the Fishers' protected LSD at $P=0.05$.

\section{Additional files}

Additional file 1: Figure S1. Leaf growth parameters under thermal stress. Graph representation of leaf growth parameters of two populations of Brassica oleracea under thermal stress conditions. Simple linear regression curves of each temperature are represented.

Additional file 2: Figure S2. Normalized chlorophyll a fluorescence transient curve. Chlorophyll a fluorescence transient curve. Data from the control were used to normalize the curve.

Additional file 3: Table S1. List of parameters of the JIP-test. Summary of parameters and formula description using data extracted from the OJIP transient.

\section{Abbreviations}

PSII: Photosystem II; $Q_{A}$ : Primary quinone-type acceptor; $Q_{B}$ : Secondary quinone-type acceptor; $A B S / R C$ : Absortion flux per reaction center; TR/RC: Trapped energy flux per reaction center; ET/RC: Electron transport flux per reaction center; DI/RC: Dissipated energy flux per reaction center.

\section{Competing interests}

The authors declare that they have no competing interests.

\section{Authors' contributions}

VMR and PV conceived and design the study. VMR, PS, TS, MEC and PV recorded physiological and anatomical data. VAV performed stomata measurements. VMR wrote the paper. MEC, PS and PV assisted in drafting the manuscript. All authors have read and approved the final manuscript.

\section{Acknowledgments}

We thank Rosaura Abilleira for technical support. This work was supported by the Spanish National Plan for Research and Development (AGL2012-35539).

We acknowledge support of the publication fee by the CSIC Open Access Publication Support Initiative through its Unit of Information Resources for Research (URICI).

\section{Author details}

${ }^{1}$ Group of Genetics, Breeding and Biochemistry of Brassicas. Misión Biológica de Galicia (MBG-CSIC), Apartado 28, 36080 Pontevedra, Spain. ${ }^{2}$ Group of Viticulture, Misión Biológica de Galicia (MBG-CSIC), Apartado 28, 36080 Pontevedra, Spain.

Received: 19 February 2015 Accepted: 28 May 2015 Published online: 16 June 2015

\section{References}

1. Finch-Savage WE, Leubner-Metzger G. Seed dormancy and the control of germination. New Phytol. 2006;171:501-23.

2. Kim DH, Doyle MR, Sung S, Amasino RM. Vernalization: Winter and the timing of flowering in plants. Annu Rev Cell Dev Biol. 2009;25:277-99.

3. Wheeler TR, Hong TD, Ellis RH, Batts GR, Morison JL, Hadley P. The duration and rate of grain growth, and harvest index, of wheat (Triticum aestivum L.) in response to temperature and $\mathrm{CO}_{2}$. J Exp Bot. 1996;47:623-30.

4. Roberts EH, Summerfield RJ. Measurement and prediction of flowering in annual crops. In: Atherton JG, editor. Manipulation of flowering. London: Butterworths; 1987. p. 17-50.

5. Ruelland E, Zachowski A. How plants sense temperature. Environ Exp Bot. 2010;69:225-32.

6. Örvar BL, Sangwan V, Omann F, Dhindsa RS. Early steps in cold sensing by plant cells: The role of actin cytoskeleton and membrane fluidity. Plant J. 2000;23:785-94 
7. Hardham AR, Gunning BE. Structure of cortical microtubule arrays in plant cells. J Cell Biol. 1978;77:14-34.

8. Müller J, Menzel D, Šamaj J. Cell-type-specific disruption and recovery of the cytoskeleton in Arabidopsis thaliana epidermal root cells upon heat shock stress. Protoplasma. 2007;230:231-42.

9. Fowler JE, Quatrano RS. Plant cell morphogenesis: Plasma membrane interactions with the cytoskeleton and cell wall. Annu Rev Cell Dev Biol. 1997;13:697-743

10. Campitelli BE, Stinchcombe JR. Testing potential selective agents acting on leaf shape in Ipomoea hederacea: Predictions based on an adaptive leaf shape cline. Ecol Evol. 2013;3:2409-23.

11. Salvucci ME, Crafts-Brandner SJ. Inhibition of photosynthesis by heat stress: The activation state of Rubisco as a limiting factor in photosynthesis. Physiol Plant. 2004;120:179-86.

12. Haque MS, Kjaer KH, Rosenqvist E, Sharma DK, Ottosen CO. Heat stress and recovery of photosystem $\|$ efficiency in wheat (Triticum aestivum L.) cultivars acclimated to different growth temperatures. Environ Exp Bot. 2014;99:1-8.

13. Ibaraki Y, Murakami J. Distribution of chlorophyll fluorescence parameter Fv/Fm within individual plants under various stress conditions. Acta Horticulturae. 2007;761:255-60.

14. Kautsky $H$, Hirsch A. Neue versuche zur kohlensäureassimilation. Naturwissenschaften. 1931;19:964

15. Strasser RJ, Govindjee. On the O-J-I-P fluorescence transient in leaves and D1 mutants of Chlamydomonas reinhartii. In: N M. Dordrecht, editor. Research in Photosynthesis. Kluwer Academic Publishers; 1992. p. 29-32.

16. Strasser RJ, Srivastava A, Tsimilli-Michael M. The fluorescence transient as a tool to characterize and screen photosynthetic samples. In: Yunus M, Pathre U, Mohanty P, editors. Probing photosynthesis: Mechanism, regulation and adaptation. London: Taylor \& Francis Publishers; 2000. p. 445-83.

17. Gomez-Campo C, Prakash S. Origin and domestication. In: Gomez-Campo C, editor. Biology of Brassica Coenospecies. Amsterdam: Elsevier Science B.V.; 1999. p. 33-58.

18. Rodríguez VM, Soengas P, Cartea E, Sotelo T, Velasco P. Suitability of an european nuclear collection of Brassica oleracea L. landraces to grow at high temperatures. J Agronomy Crop Sci. 2014;200:183-90.

19. Beck EH, Fettig S, Knake C, Hartig K, Bhattarai T. Specific and unspecific responses of plants to cold and drought stress. J Biosci. 2007;32:501-10.

20. Rizhsky L, Liang $H$, Mittler R. The combined effect of drought stress and heat shock on gene expression in tobacco. Plant Physiol. 2002;130:1143-51.

21. Yamori W, von Caemmerer S. Effect of Rubisco activase deficiency on the temperature response of $\mathrm{CO}_{2}$ assimilation rate and Rubisco activation state: Insights from transgenic tobacco with reduced amounts of Rubisco activase. Plant Physiol. 2009;151:2073-82.

22. Cochard H, Martin R, Gross P, Bogeat-Triboulot MB. Temperature effects on hydraulic conductance and water relations of Quercus robur L. J Exp Bot. 2000;51:1255-9.

23. Iglesias-Acosta M, Carmen Martinez-Ballesta M, Antonio Teruel J, Carvajal M. The response of broccoli plants to high temperature and possible role of root aquaporins. Environ Exp Bot. 2010;68:83-90.

24. Sellin A, Kupper P. Temperature, light and leaf hydraulic conductance of little-leaf linden (Tilia cordata) in a mixed forest canopy. Tree Physiol. 2007;27:679-88.

25. Armstrong AF, Wardlaw KD, Atkin OK. Assessing the relationship between respiratory acclimation to the cold and photosystem II redox poise in Arabidopsis thaliana. Plant Cell Environ. 2007;30:1513-22.

26. Williams DG, Black RA. Phenotypic variation in contrasting temperature environments: Growth and photosynthesis in Pennisetum setaceum from different altitudes on Hawaii. Funct Ecol. 1993;7:623-33.

27. Huner NPA, Palta JP, Li PH, Carter JV. Anatomical changes in leaves of Puma rye in response to growth at cold-hardening temperatures. Bot Gaz. 1981;142:55-62.

28. Rohácek K, Barták M. Technique of the modulated chlorophyll fluorescence: Basic concepts, useful parameters and some applications. Photosynthetica. 1999;37:339-63.

29. Stirbet A, Govindjee. Chlorophyll a fluorescence induction: A personal perspective of the thermal phase, the J-I-P rise. Photosynth Res. 2012;113:15-61.

30. Stirbet A, Govindjee. On the relation between the Kautsky effect (chlorophyll a fluorescence induction) and photosystem II: Basics and applications of the OJIP fluorescence transient. J Photochem Photobiol B. 2011;104:236-57

31. Brestic M, Zivcak M, Kalaji HM, Carpentier R, Allakhverdiev SI. Photosystem II thermostability in situ: Environmentally induced acclimation and genotype-specific reactions in Triticum aestivum L. Plant Physiol Biochem. 2012;57:93-105.

32. Yamane $Y$, Kashino Y, Koike H, Satoh K. Increases in the fluorescence Fo level and reversible inhibition of photosystem $\|$ reaction center by high-temperature treatments in higher plants. Photosynth Res. 1997;52:57-64.

33. Srivastava A, Guissé B, Greppin H, Strasser RJ. Regulation of antenna structure and electron transport in photosystem II of Pisum sativum under elevated temperature probed by the fast polyphasic chlorophyll a fluorescence transient: OKJIP. Biochim Biophys Acta Bioenerg. 1997;1320:95-106.

34. Koư̌il R, Lazár D, llík P, Skotnica J, Krchňák P, Nauš J. High-temperature induced chlorophyll fluorescence rise in plants at $40-50{ }^{\circ} \mathrm{C}$ : Experimental and theoretical approach. Photosynth Res. 2004;81:49-66.

35. Zushi K, Kajiwara S, Matsuzoe N. Chlorophyll a fluorescence OJIP transient as a tool to characterize and evaluate response to heat and chilling stress in tomato leaf and fruit. Sci Hortic. 2012;148:39-46.

36. Srivastava A, Strasser RJ. Stress and stress management of land plants during a regular day. J Plant Physiol. 1996;148:445-55.

37. Lazár D, Pospišil P, Nauš J. Decrease of fluorescence intensity after the K step in chlorophyll a fluorescence induction is suppressed by electron acceptors and donors to photosystem 2. Photosynthetica. 1999;37:255-65.

38. Chen LS, Cheng L. Photosystem 2 is more tolerant to high temperature in apple (Malus domestica Borkh.) leaves than in fruit peel. Photosynthetica. 2009;47:112-20.

39. Joly D, Bigras C, Harnois J, Govindachary S, Carpentier R. Kinetic analyses of the OJIP chlorophyll fluorescence rise in thylakoid membranes. Photosynthetic Res. 2005;84:107-12.

40. Duysens LNM, Sweers HT. Mechanism of the two photochemical reactions in algae as studied by means of fluorescence. In: Physiologists JSoP, editor. Studies on microalgae and photosynthetic bacteria. Tokyo: University of Tokyo; 1963. p. 353-72

41. Schansker G, Tóth S, Holzwarth A, Garab G. Chlorophyll a fluorescence: Beyond the limits of the $\mathrm{Q}_{A}$ model. Photosynth Res. 2014;120:43-58.

42. Strasser RJ, Tsimilli-Michael M, Srivastava A. Analysis of the chlorophyll a transient. In: Papageorgiou G, Govindjee, editors. Chlorophyll fluorescence: A signature of photosynthesis, advances in photosynthesis and respiration. The Netherlands: Kluwer Academic Publishers; 2004. p. 321-62.

43. Van Heerden PD, Tsimilli-Michael M, Kruger GH, Strasser RJ. Dark chilling effects on soybean genotypes during vegetative development: Parallel studies of $\mathrm{CO}_{2}$ assimilation, chlorophyll a fluorescence kinetics O-J-I-P and nitrogen fixation. Physiol Plant. 2003;117:476-91.

44. Chen LQ, Li CS, Chaloner WG, Beerling DJ, Sun QG, Collinson ME, et al. Assessing the potential for the stomatal characters of extant and fossil Ginkgo leaves to signal atmospheric $\mathrm{CO}_{2}$ change. Am J Bot. 2001;88:1309-15.

45. Abramoff MD, Magalhaes PJ, Ram SJ. Image processing with ImageJ. Biophotonics Int. 2004;11:36-42.

46. SAS Institute Inc. SAS ${ }^{\oplus} 9.2$ Enhanced logging facilities. Cary, North Carolina: SAS Inst; 2008

\section{Submit your next manuscript to BioMed Central and take full advantage of:}

- Convenient online submission

- Thorough peer review

- No space constraints or color figure charges

- Immediate publication on acceptance

- Inclusion in PubMed, CAS, Scopus and Google Scholar

- Research which is freely available for redistribution 